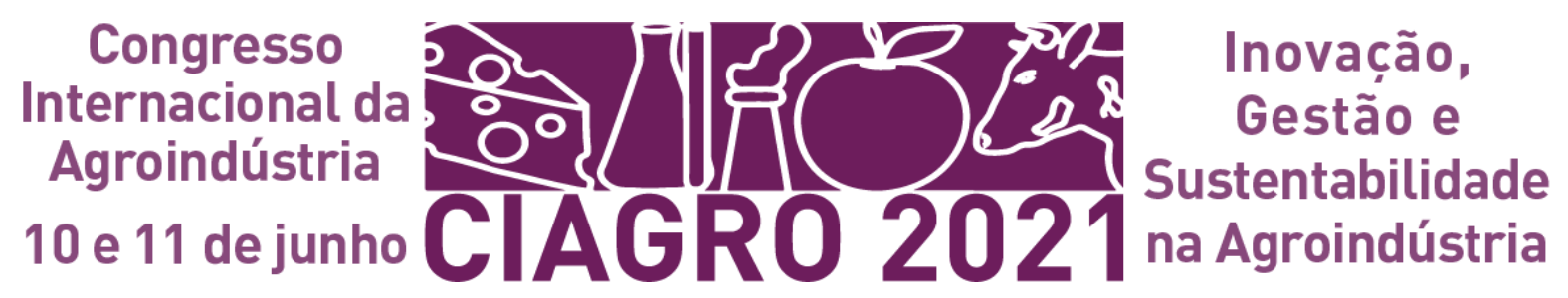

\title{
POTENCIAL DA IDENTIFICAÇÃO BACTERIANA EM QUEIJOS ARTESANAIS ATRAVÉS DE METAGENÔMICA
}

\section{POTENCIAL DE IDENTIFICACIÓN BACTERIANA EN QUESOS ARTESANALES MEDIANTE METAGENOMÍA}

\section{POTENTIAL OF BACTERIAL IDENTIFICATION IN ARTISANAL CHEESES THROUGH METAGENOMICS}

\author{
Natália Lima Myazaki ${ }^{1}$; Mariana Cardoso²; Marília Miotto ${ }^{3}$; Kátia Rezzadorii ${ }^{4}$, Silvani Verruck ${ }^{5}$
}

DOI: https://doi.org/10.31692/IICIAGRO.0198

\begin{abstract}
RESUMO
Além dos consumidores atuais serem mais exigentes em relação a alimentação por conta da saúde, a tecnologia corrobora pela busca de alimentos que possibilitam novas experiencias sensoriais. Desta forma o interesse por esses produtos estão em crescimento nos últimos anos, sendo que dentro desses grupos de alimentos os queijos artesanais de leite cru se destacam, visto que ao contrário dos queijos industrializados são produtos lácteos fermentados onde a padronização não é regra. Esses queijos são tradicionalmente produzidos e consumidos no mundo todo, sendo que suas propriedades sensoriais variam de acordo com a região na qual são fabricados, por conta da microbiota características de cada região, diferentes enzimas presentes na matéria prima que transloca para os queijos produzidos com leite que não passa por tratamento térmico, além do saber-fazer específicos. Apesar dos surtos de doenças transmitidas por alimentos terem apresentados resultados menores nos últimos anos no Brasil, dados epidemiológicos no país de DTAs relacionadas ao consumo de queijos são escassos, por conta disso o mapeamento microbiológico desses alimentos é extremamente importante para assegurar a saúde do consumidor. Visando a melhor especificidade e identificação de bactérias em alimentos, as ferramentas microbiológicas clássicas como, identificação de bactérias em placas, isolamento e identificação bioquímica estão dando espaço ao uso de ferramentas avançadas de identificação bacteriana, como o sequenciamento do genoma bacteriano. Visto que o genoma codifica informações e as propriedades dos microrganismos, a metagenômica além de permitirem a compreensão completa da ecologia bacteriana destes produtos são técnicas que independem de meios de cultivos. Desta forma, o objetivo deste estudo foi revisar estudos utilizando análise metagenômica em queijos artesanais.
\end{abstract}

Palavras-Chave: Queijos, bactérias, metagenômica.

\section{RESUMEN}

Además de que los consumidores actuales son más exigentes con la alimentación por motivos de salud, la tecnología corrobora la búsqueda de alimentos que posibiliten nuevas experiencias sensoriales. Así, el interés por estos productos ha ido creciendo en los últimos años, y dentro de estos grupos de alimentos destacan los quesos artesanales de leche cruda, ya que a diferencia de los quesos industrializados que son productos lácteos fermentados, la estandarización no es posible. Estos quesos se obtienen y

\footnotetext{
${ }^{1}$ Ciência e Tecnologia de Alimentos, Universidade Federal de Santa Catarina, natalialmya@ gmail.com

${ }^{2}$ Ciência e Tecnologia de Alimentos, Universidade Federal de Santa Catarina, mariana.fc96@gmail.com

${ }^{3}$ Dra em Ciência de Alimentos, Universidade Federal de Santa Catarina, marilia.miotto@ufsc.br

${ }^{4}$ Dra em Engenharia de Alimentos, Universidade Federal de Santa Catarina, katia.rezzadori@ufsc.br

${ }^{5}$ Dra em Ciência de Alimentos, Universidade Federal de Santa Catarina, silvani.verruck@ufsc.br
} 
consumen tradicionalmente en todo el mundo, y sus propiedades sensoriales varían según la región en la que se fabrican, debido al microbiota característico de cada región, diferentes enzimas presentes en la materia prima que pasa por quesos buscados con leche que no someterse a tratamiento térmico, además de conocimientos específicos. A pesar de que los brotes de enfermedades transmitidas por alimentos han tenido menores resultados en los últimos años en Brasil, los datos epidemiológicos en el país de DTA relacionados con el consumo de queso son escasos, por lo que el mapeo microbiológico de estos alimentos es de suma importancia para asegurar la salud del consumidor. Con el objetivo de una mejor especificidad e identificación de bacterias en los alimentos, las herramientas microbiológicas clásicas como la identificación de bacterias en placas, el aislamiento y la identificación bioquímica están dando lugar al uso de herramientas avanzadas para la identificación de bacterias, como la secuenciación del genoma bacteriano. Dado que el genoma codifica información y propiedades de los microorganismos, la metagenómica, además de permitir un conocimiento completo de la ecología bacteriana de estos productos, son técnicas que no dependen de medios de cultivo. Así, el objetivo de este estudio fue revisar los estudios que utilizan el análisis metagenómico en quesos artesanales.

Palabras Clave: Queso, bacterias, metagenómica

\section{ABSTRACT}

In addition to current consumers being more demanding in relation to food because of health, technology corroborates the search for foods that enable new sensory experiences. Thus, interest in these products has been growing in recent years, with artisanal raw milk cheeses standing out among these food groups, since unlike industrialized cheeses are fermented dairy products, standardization is not possible. These cheeses are traditionally obtained and consumed worldwide, and their sensory properties vary according to the region in which they are manufactured, due to the microbiota characteristic of each region, different enzymes present in the raw material that passes for cheeses sought after with milk which does not undergo heat treatment, in addition to specific know-how. Despite the outbreaks of foodborne diseases have had lesser results in recent years in Brazil, epidemiological data in the country of DTAs related to cheese consumption are scarce, because of this the microbiological mapping of these foods is extremely important to ensure consumer health. Aiming at better specificity and identification of bacteria in food, the classic microbiological tools such as identification of bacteria on plates, isolation and biochemical identification are giving rise to the use of advanced tools for bacterial identification, such as sequencing the bacterial genome. Since the genome encodes information and properties of microorganisms, metagenomics, in addition to allowing a complete understanding of the bacterial ecology of these products, are techniques that do not depend on culture media. Thus, the aim of this study was to review studies using metagenomic analysis in artisanal cheeses.

Keywords: Cheese, bacteria, metagenomics.

\section{INTRODUÇÃO}

O mercado de produtos alimentícios premium, gourmet e artesanais é responsável por uma movimentação financeira significativa no mundo todo, influenciada principalmente pelo aumento da facilidade na obtenção de informações que indiretamente incentivam os consumidores a valorizarem mais a culinária e experimentarem novas experiências sensoriais (BARBOSA et al., 2020). Além de estarem entre os produtos lácteos mais exportados pelo Brasil, os queijos são os que apresentam maior taxa de crescimento de vendas nos últimos anos no mercado externo (CARVALHO; ROCHA, 2019). Sendo que além da produção industrial, há também a produção de forma artesanal que, por sua vez, pode apresentar-se como a principal fonte de renda principalmente de pequenos produtores rurais (CORREIA; ASSIS, 2017). 
Os queijos artesanais brasileiros são aqueles elaborados por métodos tradicionais que possuem vinculação e valorização territorial, regional ou cultural e que respeitam os protocolos de elaboração estabelecidos para cada variedade (BRASIL, 2019). Por poderem ser elaborados a partir do leite cru, ou seja, leites que não passaram por tratamentos térmicos superiores a $40^{\circ} \mathrm{C}$, os queijos artesanais de diferentes regiões apresentam derivações em relação a textura, sabor e aroma (CARVALHO et al., 2016; EPAMIG, 2019), fatores esses que os diferenciam dos queijos industriais que são padronizados. Uma vez que, existem tanto variações microbianas e enzimáticas dos locais que os leites foram produzidos quanto derivações do “'saber-fazer' de cada região (EPAMIG, 2019; SILVA, 2007). Apesar da utilização do leite cru, uma série de condições são impostas durante toda a elaboração de queijos artesanais a fim de garantir a segurança do produto que será comercializado, evitar contaminações (CARVALHO et al., 2016; EPAMIG, 2019; PEREIRA, 2006), não prejudicar o processo fermentativo e não provocar alterações sensoriais (SALINAS, 2002).

Estudos da composição microbiana de produtos fermentados já foram realizados por métodos tradicionais de contagem de bactérias em placas, isolamento e identificação bioquímica dos microrganismos (SHARMA; LEE; PARK, 2020). Porém, sabe-se que somente microrganismos facilmente cultiváveis podem ser detectados por metodologias microbiologicas convencionais, enquanto os que necessitam de meios mais complexos ou que se encontram injuriados não é possível a detecção (SHARMA; LEE; PARK, 2020). Pela dificuldade de detecção microbiana por métodos tradicionais, ferramentas mais avançadas estão sendo aplicadas para a identificação e caracterização da microbiota presente em produtos artesanais, como por exemplo o sequenciamento genético de amplo espectro dos microrganismos. Com o desenvolvimento da microbiologia molecular e a descoberta de que o DNA carrega informações hereditárias, indicando que todas as propriedades dos microrganismos estão criptografadas no genoma (MARDANOV; KADNIKOV; RAVIN, 2018), tornou-se possível o uso de métodos moleculares para identificação dos microrganismos presentes em alimentos, entre estes os produtos fermentados (FRANCIOSA et al., 2018).

Neste sentido, a metagenômica destaca-se por executar o sequenciamento para a identificação de toda a microbiota de uma amostra através de genes marcadores como o gene $16 \mathrm{~S}$ para as bactérias. Esta metodologia apresenta resultados a nível taxonômico do filo até a espécie do microrganismo identificado, utilizando ferramentas de bioinformática e bancos de ecologia. A partir dessas metodologias é possível identificar a microbiota de qualquer alimento, entre eles os queijos artesanais (FRANCIOSA et al., 2018). Desta forma, o objetivo foi revisar estudos utilizando análise metagenômica em queijos artesanais. 


\section{IDENTIFICAÇÃO BACTERIANA POR SEQUENCIAMENTO GENÔMICO}

As doenças transmitidas por alimentos (DTAs) são causadas quando há a ingestão de alimentos ou água contaminadas por microrganismos patogênicos ou por suas toxinas (EMBRAPA, 2013), sendo que em território nacional os surtos por DTA são causados principalmente por bactérias, sendo os mais recorrentes: Escherichia coli, Salmonella spp., Staphylococcus aureus, coliformes e Bacillus cereus (ANVISA, 2019). Porém no Brasil dados epidemiológicos de DTAs relacionadas ao consumo de queijos são escassos (CARVALHO $e t$ al., 2019), sendo que o mapeamento microbiológico de queijos de leite cru é extremamente importante para assegurar a saúde do consumidor (KAMIMURA, 2018).

O leite é uma matéria de composição complexa e completa (proteínas, gorduras, carboidratos, minerais e vitaminas), o que o torna um ambiente propício para o desenvolvimento de microrganismos (O’SULLIVAN; COTTER, 2017). Para que a inocuidade do leite seja mantida cuidados com a obtenção, armazenamento, processamento, controle da carga microbiológica e determinação dos tipos de microrganismos devem seguir as legislações evitando-se então infeções, intoxicações alimentares, prejuízos nutricionais e sensoriais (FREO; REOLON, 2006; IRKIN, 2010), principalmente quando se trata de queijos elaborados a partir do leite cru.

A identificação de cepas patogênicas e de bactérias é de extrema importância para o processo industrial (CUNHA, 2016), uma vez que além de poderem ser fontes de contaminação, cada microrganismo apresenta uma rota metabólica diferente, e quanto mais especifica for a aplicação mais otimizado poderá ser o processo (VAN BELKUN et al., 2007). Existem várias técnicas microbiológicas para identificar e caracterizar a diversidade de bactérias que estão presentes nos queijos artesanais, sendo que os métodos que dependem do cultivo são os mais tradicionais (BERESFORD et al., 2001). Ademais, na maioria das vezes essas técnicas clássicas devem ser utilizadas com objetivos precisos, uma vez que apresentam muitas retenções práticas como a sensibilidade do método, além de ser um trabalho exaustivo no laboratório requerendo muito tempo (VAN BELKUN et al., 2007; WOLSKA; SZWEDA, 2012). Também há dificuldade em relação a cultivar as bactérias em placas, uma vez que são diversos os meios de cultura e o escolhido deve ser relacionado com características específicas do microrganismo de interesse (BRUNO; CARVALHO, 2009) e a temperatura de incubação também interfere no crescimento das bactérias desejadas (CARVALHO, 2007).

Por conta disso o surgimento de métodos de tipagem baseados em sequenciamento de DNA surgiram como alternativas para os métodos de identificação clássicos fenotípicos 
(KAZOU et al., 2021). Essa nova forma de organizar e classificar os organismos com técnicas moleculares tornou-se mais rápido, com resultados mais fidedignos, além de ser de fácil reprodutividade. Isso porque, os métodos detectam as células nos seus mais diversos estados, desde as viáveis até aquelas lisadas ou danificadas (O'SULLIVAN et al., 2013). Além disso, os dados são compartilhados de forma on-line via plataformas digitais, facilitando dessa forma a interpretação dos dados obtidos pelas técnicas de tipagem por sequenciamento (CUNHA, 2016).

O sequenciamento do DNA é um método da biologia molecular que tem como finalidade determinar a ordem exata das bases nitrogenadas de uma parte ou do todo dessa molécula (FIETTO; MACIEL, 2015). Com os métodos de tipagem genotípicas é possível avaliar as variações que ocorrem em partes ou na totalidade dos genomas de microrganismos, sendo que qualquer um deles quando realizados com eficiência algumas informações são obtidas, como: expressão gênica diferencial, estrutura e função dos genes, diversidade genética, presença de elementos móveis no genoma, presença de genes adquiridos por transferência lateral, relações evolutivas e construção de mapas metabólicos (NIERMAN et al., 2000).

O sequenciamento dito clássico, é a técnica de Sanger que com os anos passou por aprimoramentos como, por exemplo a incorporação de corantes emissores de fluorescência (FIETTO; MACIEL, 2015). Esta técnica baseia-se na replicação do DNA molde por ação de uma enzima (DNApolimerase) pela técnica de Reação em Cadeia da Polimerase (PCR), tal replicação pode ser interrompida em diferentes regiões por interferência de nucleotídeos (didesoxirribonucleotídeos).

O poder discriminatório das cepas está diretamente relacionado com o tamanho do fragmento que é sequenciado e por conta disso existem três técnicas de sequenciamento, sendo elas: Tipagem por Sequenciamento de Único Locus (SLST), Tipagem por Sequenciamento de Múltiplos Loci (MLST) e Tipagem por Sequenciamento Completo do Genoma (WGST) (CUNHA, 2016). No método SLST, por sequenciar uma quantidade limitada de locus de DNA, a região selecionada deve apresentar bastante variação de sequenciamento gênico e deve-se utilizar um marcador específico para cada espécie bacteriana a ser identificada. Apesar disso os resultados encontrados em diversas analises são facilmente comparados pois, as informações são armazenadas em banco de dados on-line (HARMSEN et al., 2003; VAN BELKUM et al., 2007; WOLSKA; SZWEDA, 2012).

A técnica MLST que surgiu para suprir a lacuna existente no método citado anteriormente foi aplicada pela primeira vez em 1998 em estudos genéticos de bactérias patogênicas (MAIDEN et al., 1998), por conta da sua eficiência em relacionar as espécies (DE 


\section{POTENCIAL DA IDENTIFICAÇÃO BACTERIANA EM QUEIJOS}

VOS, 2011). Os métodos de análise dessa técnica podem ser baseados em duas estratégias: a primeira delas é dependente dos alelos, ignorando a diferença entre os nucleotídeos presentes e por conta disso os resultados não são tão acurados, uma vez que eles não podem distinguir uma única mudança de base em múltiplas loci das mutações do mesmo número de loci (MAIDEN, 2013; PÉREZ-LOSADA et al., 2013). Já a segunda estratégia, são métodos baseados nas sequências dos nucleotídeos (PÉREZ-LOSADA et al., 2013), geralmente 450-500 pares de base são sequenciados de sete genes referência (CUNHA, 2016), ou seja, é com a determinação da sequência dos nucleotídeos que o grau de parentesco bacterianos são determinados (PÉREZLOSADA et al., 2013).

Por ambas as técnicas citadas anteriormente apresentarem limitações quanto a abertura genômica que dificulta a especificação e diferenciação de tipagem de algumas espécies surgiu então a técnica WGST. Sinônimo de alta sensibilidade técnica, esse método é capaz de diferenciar cepas que apresentam diferenças em apenas um nucleotídeo (CUNHA, 2016). Apesar dos dados dessa técnica estar disponível de forma online, a interpretação da enorme gama de dados e a determinação dos marcadores genéticos ainda são barreiras para essa tecnologia (LARSEN et al., 2012; SABAT et al., 2013; VAN BELKUM et al., 2007).

O sequenciamento do gene $16 \mathrm{~S}$ rRNA em específico é realizado pois, possibilita a caracterização dos isolados de forma rápida e segura (CLARRIDGE, 2004). Nesta parte do rRNA há regiões conservadas que permitem o desenvolvimento de primers direcionados a todas as bactérias e regiões de abrangência com sequências específicas de espécies (COCOLIN; RANTSIOU, 2007; ERCOLINI, 2004), ou seja, com a amplificação da região 16S rRNA é possível comparar quais os pares de bases nitrogenadas estão diferentes entre as espécies e que são responsáveis pela diferenciação das suas características (COCOLIN; RANTSIOU, 2007). Regiões diferentes desse gene geralmente apresentam número limitado de sequências (DOULGERAKI, 2012; MAUKONEN; SAARELA, 2009; NOCKER; BURR; CAMPER, 2007).

A especificidade da identificação bacteriana pode ser ainda mais ampliada pela identificação taxonômica de regiões hipervariáveis como, a V3 e a V4 (ZHANG et al., 2018). Com o sequenciamento da região V3 é possível diferenciar a maioria das bactérias, isso por que ela apresenta o maior número de sítios variáveis. Já com a análise da região V4 é possível saber com mais eficácia a aproximação familiar dos microrganismos presentes na amostra. Desta forma, a análise simultânea de ambas as regiões citadas permite uma maior especificidade do microbioma presente na amostra, uma vez que fragmentos de tamanho mais apropriados são analisados (CHRISTOFF, 2016) 
Atualmente o interesse por sequenciadores automáticos vem crescendo, pois assim é possível que a genotipagem ocorra de forma mais ampla. O sequenciamento de milhões de fragmentos de forma paralela em vez do sequenciamento ser de um único fragmento de DNA e maior velocidade de obtenção de informações com menor custo. Além disso, houve o acoplamento da técnica com tecnologias digitais como a plataforma Illumina Miseq que apresenta princípios semelhantes ao método Sanger (COLLINS; MORGAN; PATRINOS, 2003). No princípio da plataforma também há a síntese de uma fita complementar ao DNA alvo utilizando DNA polimerase e nucleotídeos terminadores marcados, porém são utilizados fluoróforos que são responsáveis pela decodificação das imagens de cada nucleotídeo e consequentemente o sequenciamento da região de interesse (FIETTO; MACIEL, 2015).

O termo metagenômica que foi utilizado pela primeira vez no final do século XX definia a técnica como a avaliação dos materiais genéticos isolados diretamente das amostras, sem desta forma depender de meios de cultura (HANDELSMAN, 2004). Justamente por ser um método independente de cultivo que analisa as sequências de nucleotídeos, tornou-se uma das principais formas de estudo de microrganismos isolados (HUGENHOLTZ; TYSON, 2008). Visto que naquela época já se sabia que todas as informações hereditárias dos organismos estavam presentes na molécula de DNA e desde então a ecologia microbiana ganhou um novo patamar com o sequenciamento do rRNA de organismos obtidos diretamente do ambiente (MARDANOV; KADNIKOV; RAVIN, 2018).

A identificação mais acurada dos microrganismos pelas técnicas genômicas ou metagenômica possibilitaram extrapolar as interações da microbiota com o produto, sendo esse um fator de extrema relevância para as indústrias uma vez que influencia na qualidade final do produto com o desenvolvimento de características sensorais e reológicas e também na segurança dos mesmos com a deterioração quando há a presença de organismos não desejáveis (RIOS et al., 2020).

Dos produtos de origem animal o leite pode ser considerado o mais completo em termos nutricionais (RIBEIRO, 2005). Na elaboração de queijos em geral, a matéria prima principal, deve apresentar excelente qualidade microbiológica a fim de não prejudicar o processo fermentativo, não provocar alterações sensorais e principalmente não causar danos à saúde do consumidor (SALINAS, 2002). Apesar dos métodos de identificação bacteriana que utilizam a caracterização fenotípica até hoje serem muito utilizados, testes clássicos não são muito eficientes para separar espécies fenotipicamente relacionadas, pois muitas vezes não permitem a separação genética de subespécies (DELGADO; MAYO, 2004). Com tais análises, a cultura como um todo é analisada e o metabolismo individual de cada célula acaba sendo ignorado, 


\section{POTENCIAL DA IDENTIFICAÇÃO BACTERIANA EM QUEIJOS}

desta forma aquelas culturas que estão viáveis, porém não cultiváveis acabam não sendo reveladas (JEPRAS et al., 1995; NEBE-VON-CARON; BADLEY, 2000).

Por conta disso o surgimento de técnicas que ampliassem o conhecimento sobre os microrganismos foi necessário como, por exemplo, o surgimento da técnica de sequenciamento genético em 1975 (SANGER; COULSON, 1975). Com a possibilidade de identificar o mapeamento genômico de microrganismos em alimentos fermentados há um crescente interesse na aplicação destas metodologias na área. Na Tabela 1 são apresentados alguns estudos da diversidade microbiana em queijos utilizando sequenciamento genético de amplo espectro (metagenômica).

Tabela 01: Diversidade microbiana em queijos utilizando ferramentas metagenômicas.

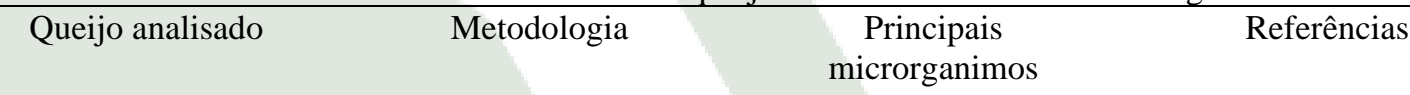

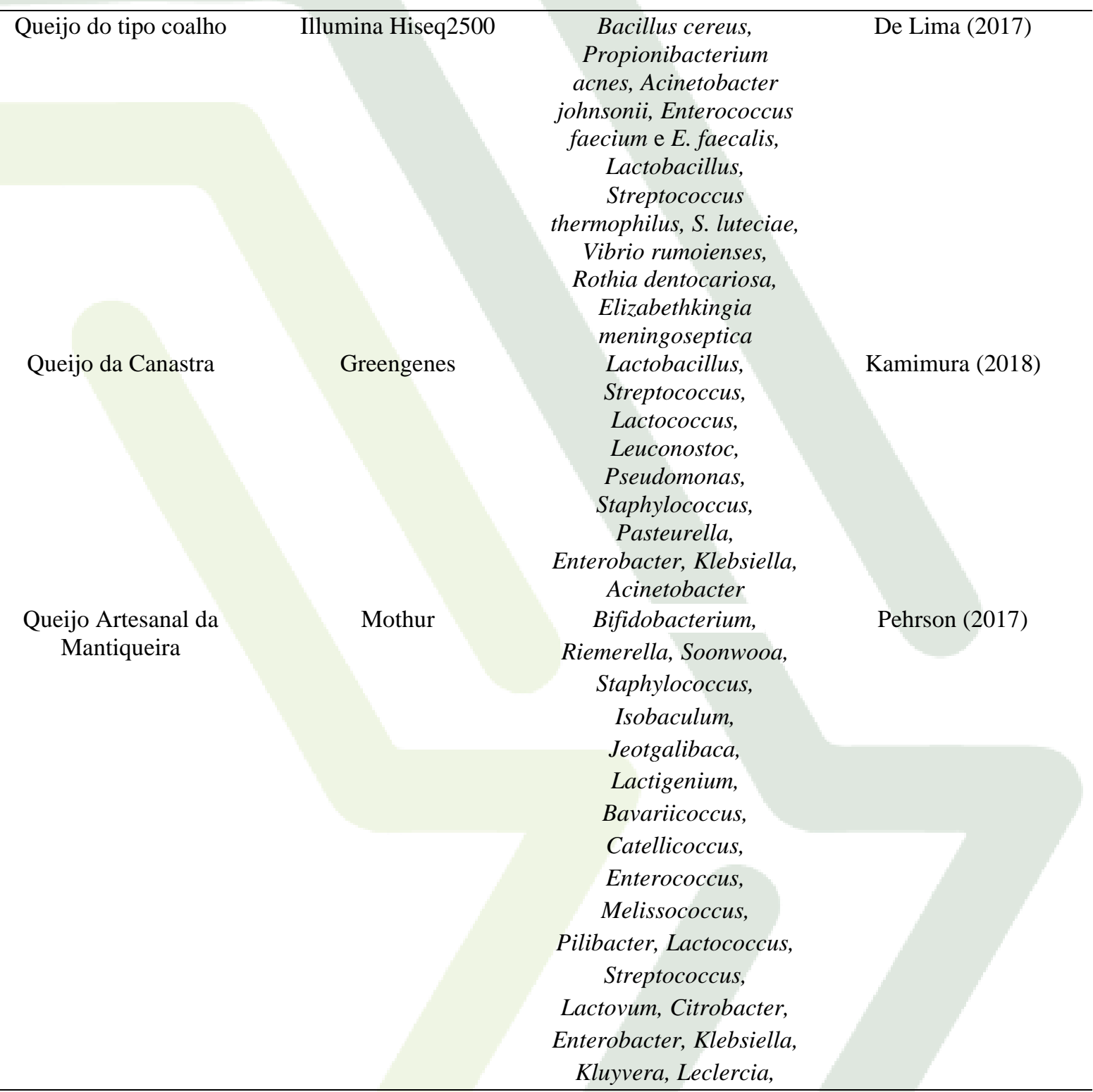




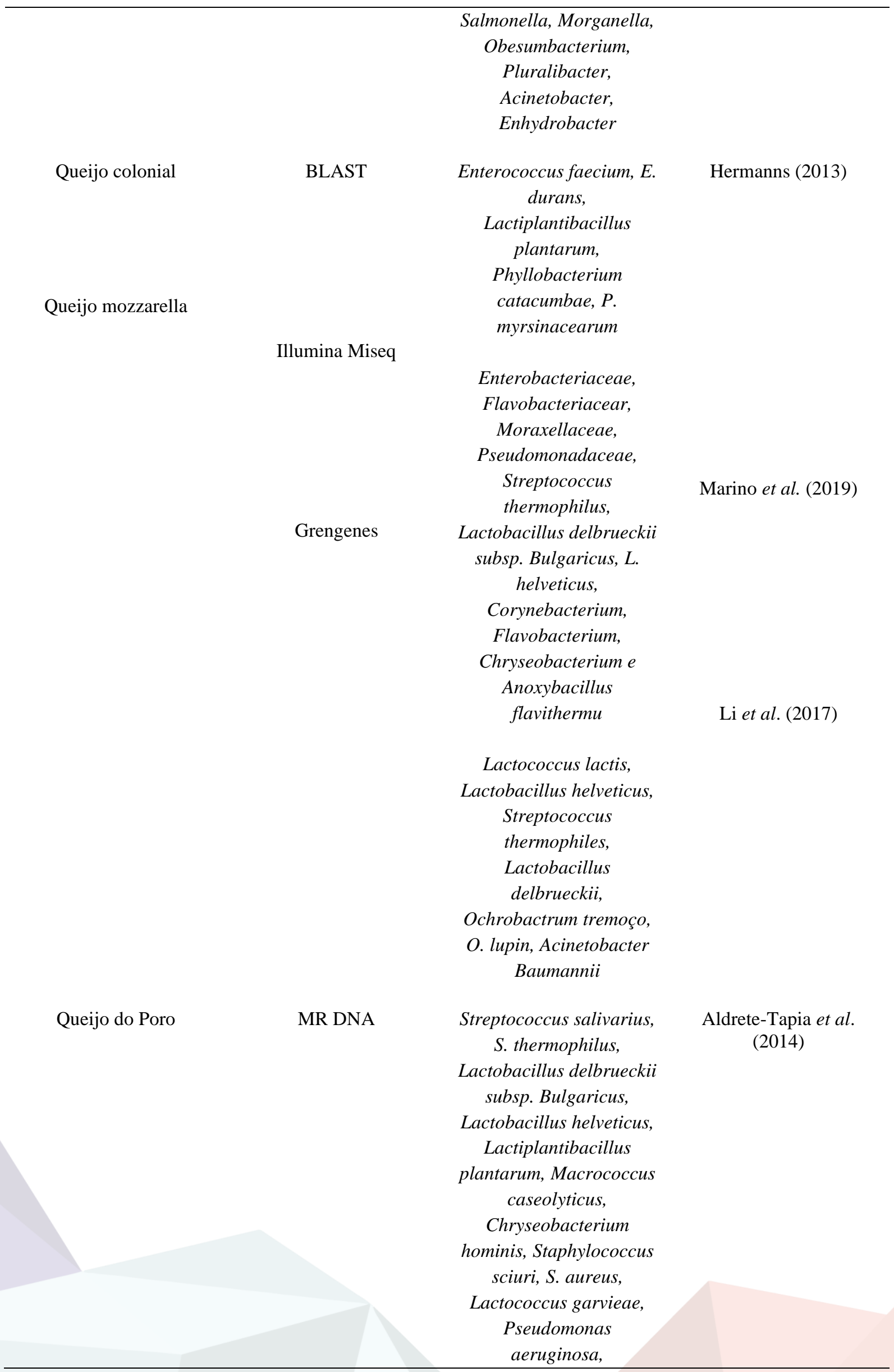




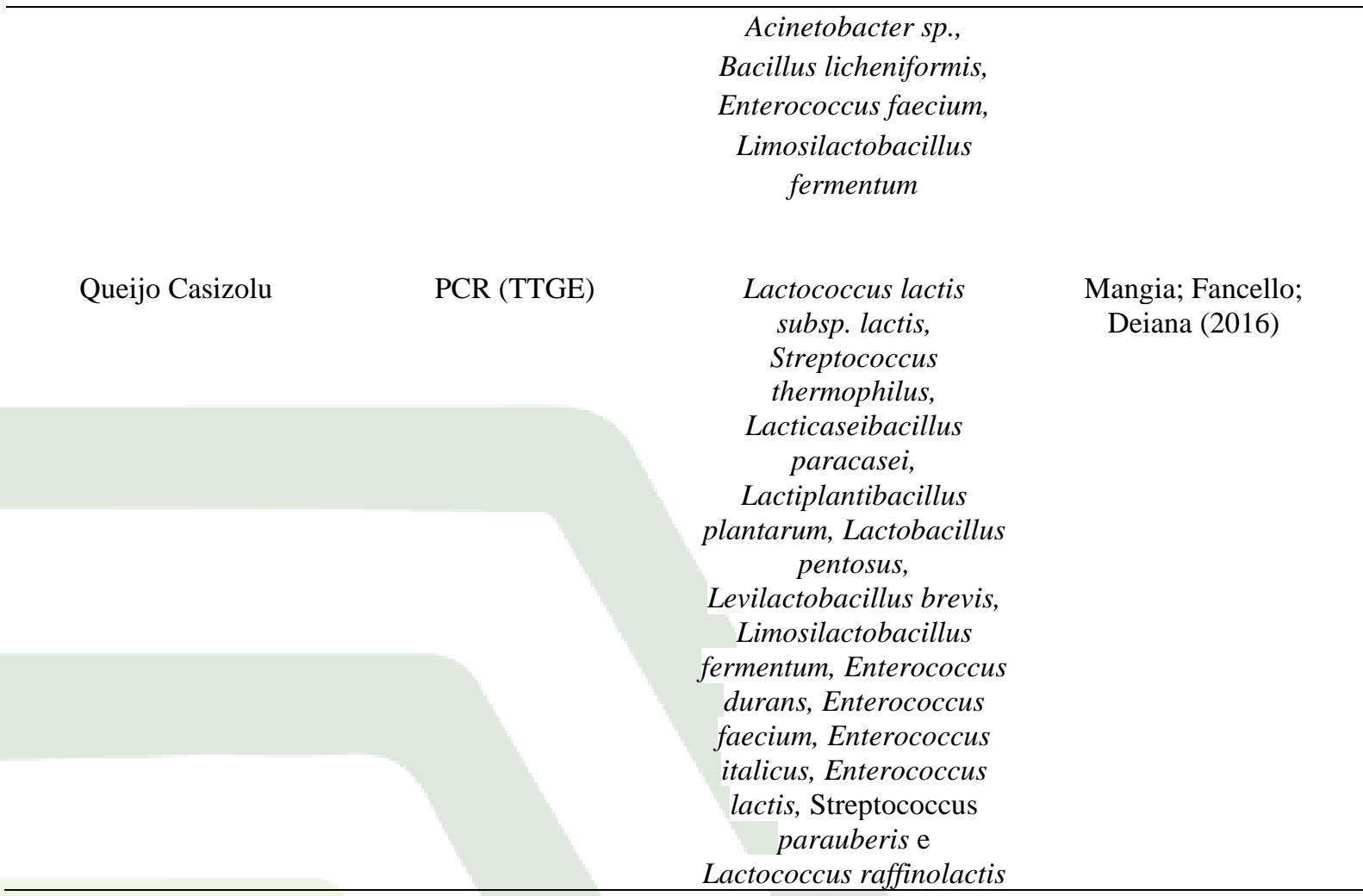

Fonte: Própria (2019).

De Lima et al. (2017), Kamimura (2018) e Hermanns (2013) realizaram o sequenciamento genômico (16S rRNA) da comunidade microbiana derivada do queijo coalho elaborados com leite cru e pasteurizado, queijo da Canastra e queijo Colonial, respectivamente. Todos analisaram como a comunidade influência nos sabores, texturas e aromas do produto final, e concluíram que havia a presença tanto de bactérias patogênicas quanto de bactérias benéficas que fazem parte da microbiota de derivados lácteos. Pehrson (2017), avaliou a efetividade na aplicação de microrganismos probióticos em relação a melhor qualidade microbiológica e características fermentativas do queijo Artesanal das Terras Altas da Serra da Mantiqueira em diferentes estações do ano. Neste trabalho o autor concluiu que houveram diferenças significativas das comunidades microbianas do queijo conforme havia mudanças sazonais e na incorporação de culturas probióticas.

Marino et al. (2019), por análise metagenômica avaliaram as diferenças das culturas bacterianas do queijo mussarela de búfala e de vaca, além disso abordaram a relevância da metodologia em auxiliar a garantia da segurança alimentar quanto a diferenciação dos microrganismos e deterioração do produto. Li et al. (2017) avaliaram a pouco estudada diversidade bacteriana do queijo Cazaquistão e compararam os resultados com análises de outros países em bancos de dados, neste estudo concluíram que a região geográfica realmente é responsável pela diversidade da microbiota. Aldrete-Tapia et al. (2014) analisaram as 
influências do processo produtivo na elaboração do queijo Poro em relação a comunidade de bactérias. Os autores concluíram que um dos fatores que mais influenciaram nas características finais do queijo foram as diversidades que ocorrem nas comunidades bacterianas encontradas nos leites coletados em períodos de seca e em períodos chuvosos, sendo que esse fator acaba interferindo no processo produtivo e na etapa de maturação do queijo. Mangia; Fancello; Deiana (2016) foram pioneiros na avaliação das espécies de bactérias que estavam presentes no primeiro mês de maturação do queijo Casizolu e concluíram que as espécies Lactococcus lactis subsp. lactis, Streptococcus thermophilus e Lacticaseibacillus paracasei foram as principais espécies bacterianas envolvidas na fabricação e maturação do queijo italiano.

A singularidade das variedades dos queijos é influenciada por fatores já conhecidos como, a região de produção, a composição do leite utilizado, umidade da localidade, altitude, temperatura e microrganismos iniciadores (CÓRDOVA et al., 2016; IDE; BENEDET, 2001). Por conta disso os estudos das comunidades bacterianas desse tipo de alimento fermentado são extremamente relevantes, pois eles auxiliam tanto na otimização do processamento industrial quanto no entendimento das interações desses microrganismos com a matéria-prima (RIOS et $a l ., 2020$ ). Porém além das análises serem de fácil replicabilidade a interpretação dos resultados também deve ser facilitada, facilidades essas que ocorreram com os avanços das técnicas que não necessitam da utilização de meios de cultura (AMANN; LUDWIG; SCHLEIFER,1995; ANDREOTE, 2007; HUGHES et al., 2001).

\section{CONSIDERAÇÕES FINAIS}

Os queijos elaborados com leite cru apresentam naturalmente uma microbiota rica e que exerce grande influência no processo de maturação e nas características finais do produto. As técnicas de identificação microbiana em alimentos que não dependem de meios de cultivo foram bastante aprimoradas. No entanto, o desenvolvimento de técnicas de sequenciamento de última geração (NGS) permitem um estudo ainda mais detalhado na identificação dos microrganismos presentes nos queijos, auxiliando na garantia de que o produto que está sendo comercializado não apresenta riscos à saúde dos consumidores e quando necessário pode contribuir com melhorias nos processos produtivos com a implementação de boas práticas de fabricação e melhorias nas práticas agropecuárias.

\section{REFERÊNCIAS}

ALDRETE-TAPIA, A. et al. High-throughput sequencing of microbial communities in Poro 
cheese, an artisanal Mexican cheese. Food Microbiology, v. 44, p. 136-141, 2014. DOI: 10.1016/j.fm.2014.05.022.

AMANN, R. I; LUDWIG, W.; SCHLEIFER, K-H. Phylogenetic identification and in situ detection of individual microbial cells without cultivation. Microbiology Reviews, v. 59, n. 1, p. 143-69, 1995. PMID: 7535888.

ANDREOTE, F. D. Fatores determinantes na composição da comunidade bacteriana associada às plantas. 2007. $184 \mathrm{f}$. Tese (Doutorado em Genética e Melhoramento de Plantas) - Escola Superior de Agricultura Luiz de Queiroz, Universidade de São Paulo, Piracicaba, 2007. DOI: 10.11606/T.11.2007.tde-28112007-101523.

ANVISA. Ministério da Saúde. Secretaria de Vigilância em Saúde. Coordenação-Geral de Doenças Transmissíveis. Surtos de doenças transmitidas por alimentos no Brasil, Informe 2018. Brasília, D.F., 2019. 16 p. Disponível em: http://portalarquivos2.saude.gov.br/images/pdf/2019/fevereiro/15/Apresenta----oSurtosDTA---Fevereiro-2019.pdf.

BARBOSA, L. et al. As tendências da alimentação. Brasil Food Trends 2020. Campinas: ITAL, 2020. Cap. 3, p. 39-47. Disponível em: https://alimentosprocessados.com.br/arquivos/Consumo-tendencias-e-inovacoes/BrasilFood-Trends-2020.pdf.

BERESFORD, T. P. et al. Recent advances in cheese microbiology. International Dairy Journal, v. 11, n. 4-7, p. 259-274, 2001. DOI: 10.1016/s0958-6946(01)00056-5.

BJÖRKSTÉN, B. et al. Allergy development and the intestinal microflora during the first year of life. Journal of Allergy and Clinical Immunology, v. 108, n. 4, p. 516-520, 2001. DOI: 10.1067/mai.2001.118130.

BRASIL, Ministério da Agricultura Pecuária e do Abastecimento. Instrução Normativa $\mathrm{N}^{\circ}$ 73, de 23 de setembro de 2019. Estabelecer, em todo o território nacional, o Regulamento Técnico de Boas Práticas Agropecuárias destinadas aos produtores rurais fornecedores de leite para a fabricação de produtos lácteos artesanais, necessárias à concessão do selo ARTE, na forma desta Instrução Normativa e do seu Anexo. Brasil: Diário Oficial da União, Brasília, 2019.

BRUNO, L. M; CARVALHO, J. D. G. Microbiota lática de queijos artesanais. Fortaleza (CE): Embrapa Agroindústria Tropical; 2009. Documentos 124. 29p. ISSN 1677-1915, 124.

CARVALHO, G. R.; ROCHA, D. T. O leite em 2018 e perspectivas para 2019. In: EMBRAPA (org.). Anuário gado leite 2019. Texto Comunicação Corporativa, 2019. p. 1012. Disponível em: file:///C:/Users/natal/Downloads/Anuario-LEITE-2019\%20(1).pdf.

CARVALHO, J. D. G. Caracterização da microbiota lática isolada de queijo de coalho artesanal produzido no Ceará e de suas propriedades tecnológicas. 2007. $154 \mathrm{f}$. Tese (Doutorado em Tecnologia de Alimentos) - Universidade Estadual de Campinas, Campinas. 2007. 
CARVALHO, M. de M. et al. A produção de queijo colonial artesanal no munícipio de Seara, estado de Santa Catarina, frente a legislação brasileira. Revista Instituto de Laticínios Cândido Tostes. Juiz de Fora, v. 70, n. 5, p. 253-261, 2016. DOI: 10.14295/22386416.v70i5.463.

CARVALHO, M. de M. et al. Traditional Colonial-type cheese from the south of Brazil: A case to support the new Brazilian laws for artisanal cheese production from raw milk. Journal of Dairy Science, v. 102, n. 11, p. 9711-9720, 2019. DOI: 10.3168 / jds.201916373.

CHRISTOFF, A. P. Utilizando marcadores moleculares para identificação de microorganismos. Florianópolis, SC: Neoprospecta, 2016. E-book. Disponível em: file:///C:/Users/natal/Downloads/TCC\%20Bruna\%20Marchesan\%20Maran\%20vers\%C3\% A3o\%20final\%20esse.pdf.

CLARRIDG, J. E. Impact of $16 \mathrm{~S}$ rRNA Gene Sequence Analysis for Identification of Bacteria on Clinical Microbiology and Infectious Diseases. Clinical Microbiology Reviews, v.17, n. 4, p. 840-862, 2004. DOI:10.1128/cmr.17.4.840-862.2004.

COCOLIN, L.; RANTSIOU, K. Sequencing and expression analysis of sakacin genes in Lactobacillus curvatus strains. Applied Microbiology and Biotechnology, v. 76, n. 6, p. 1403-1411, 2007. DOI: 10.1007/s00253-007-1120-8.

COLLINS, F. S.; MORGAN, M.; PATRINOS, A. The Human Genome Project: Lessons from Large-Scale Biology. Science, v. 300, n. 5617, p. 286-290, 2003. Doi: 10.1126/science.1084564.

CÓRDOVA U.A. et al., O Queijo Artesanal Serrano Como Fator de Desenvolvimento Nos Campos de Altitude do Sul do Brasil. EPAGRI. 2016. Disponível em:http://fidamercosur.org/claeh/images/2015/2_Concurso_BPAF/Asociativismo/QueijoAr tesanalSerrano.pdf.

CORREIA, V. T. da V.; ASSIS, I. C. L. de. Queijos artesanais: revisão de literatura. Revista eletrônica Nutri Time, v. 14, n. 6, p. 8001-8008, 2017. ISSN: 1983-9006.

CUNHA, P. Métodos de tipagem microbiológica para o rastreamento e controle de surtos. Florianópolis, SC: Neoprospecta, 2016. E-book. Disponível em: file:///D:/FACULDADE/TCC\%20NOVO/M\%C3\%89TODOS+DE+TIPAGEM+MICROBI OL\%C3\%93GICA\%20portugu\%C3\%AAs.pdf.

DE LIMA, J. M. P. Avaliação do microbioma do queijo de coalho. 2017. 61 f. Dissertação (Mestrado em Ciência Animal) - Universidade Federal Rural do Semi-Árido, Mossoró, 2017.

KAMIMURA, B. A. A Metagenomic Approach to the Study of Microbial Ecology and Safety of Brazilian Artisanal Cheeses: Bacterial diversity of artisanal cheese processing environment from Serra da Canasta region. 2018. 154 f. Tese (Doutorado em Ciência de Alimentos) - Universidade Estadual de Campinas, Campinas, 2018.

DE VOS, P. Multilocus Sequence Determination and Analysis. Methods in Microbiology, v. 38, cap. 17, p. 385-407, 2011. DOI: 10.1016/b978-0-12-387730-7.00017-6. 
DELGADO, S.; MAYO, B. Phenotypic and genetic diversity of Lactococcuus lactis and Enterococcus spp. strains isolated from Northern Spain starter-free farmhouse cheeses. International Journal of Food Microbiology, v. 90, n. 3, p. 309-319, 2004. DOI: 10.1016/s0168-1605(03)00323-4.

DOULGERAKI, A. I. et al. Spoilage microbiota associated to the storage of raw meat in different conditions. International Journal of Food Microbiology, v.157, n. 2, p. 130-141, 2012. DOI: 10.1016/j.ijfoodmicro.2012.05.020.

EMBRAPA. Empresa Brasileira de Pesquisa Agropecuária. Patógenos emergentes em alimentos. Fortaleza, CE, 2013. 20 p. Disponível em: https://ainfo.cnptia.embrapa.br/digital/bitstream/item/90041/1/DOC13002.pdf.

EPAMIG. Queijo Minas Artesanal - principais problemas de fabricação: manual técnico de orientação ao produtor, p. 40, 2019. ISBN 978-85-99764-43-5.

ERCOLINI, D. PCR-DGGE fingerprinting novel strategies for detection of microbes in food. Journal of Microbiological Methods, v. 56, n. 3, p. 297-314, 2004. DOI: 10.1016/j.mimet.2003.11.006.

FIETTO, J. L. R.; MACIEL, T. E. F. Sequenciando genomas. In: MOREIRA, Leandro Marcio (org.). Ciências genômicas: fundamentos e aplicações. Ribeirão Preto: Sociedade Brasileira de Genética, 2015. p. 27-64. ISBN 978-85-89265-22-5.

FRANCIOSA, I. et al. Sausage fermentation and starter cultures in the era of molecular biology methods. International Journal of Food Microbiology, v. 279, p. 26-32, 2018. DOI: 10.1016/j.ijfoodmicro.2018.04.038.

FREO, J. D.; REOLON, J. Qualidade dos produtos derivados da carne e leite, industrializados pelas agroindústrias de Frederico Westphalen, RS. Revista Higiene Alimentar, v. 20, n. 140, p. 53-59, 2006.

HANDELSMAN, J. Metagenomics: application of genomics to uncultured microorganisms. Microbiology and Molecular Biology Reviews, v. 68, n. 4, p. 669-685, 2004. DOI: 10.1128/MMBR.68.4.669-685.2004.

HARMSEN, D. et al. Typing of methicillin-resistant Staphylococcus aureus in a university hospital setting using a novel software for spa-repeat determination and database management. Journal of Clinical Microbiology, v. 41, n. 12, p. 5442-5448, 2003. DOI: $10.1128 /$ jcm.41.12.5442-5448.2003.

HERMANNS, G. Potencial bacteriocinogênico e probiótico de bactérias ácido láticas isoladas de leite e queijos artesanais. 2013. $101 \mathrm{f}$. Tese (Doutorado em Ciência e Tecnologia de Alimentos) - Universidade Federal de Santa Maria, Santa Maria, 2013.

HUGENHOLTZ, P.; TYSON, G. W. Microbiology: metagenomics. Nature, v. 455, n. 7212, p. 481-3, 2008. DOI: 10.1038/455481a.

HUGHES, J. B. et al. Counting the uncountable: statistical approaches to estimating microbial diversity. Applied and Environmental Microbiology, v. 67, v. 10, p. 4399-406, 
200. DOI: 10.1128/aem.67.10.4399-4406.2001.

IDE, L. P. A.; BENEDET, H. D. Contribuição ao conhecimento do queijo colonial produzido na região serrana do estado de Santa Catarina, Brasil. Ciência Agrotecnica, Lavras, v.25, n.6, p.1351- 1358, 2001.

IRKIN, R. Determination of microbial contamination sources for use in quality management of cheese industry: "Dil', cheese as an example. Journal of Consumer Protection and Food Safety, v. 5, n, 1, p. 91-96, 2010. DOI: 10.1007 / s00003-009-0525-y.

JEPRAS, R. I. et al. Development of a robust flow cytometric assay for determining numbers of viable bacteria. Applied and Environmental Microbiology, v.61, n.7, p.2696-2701, 1995. DOI:10.1128/AEM.61.7.2696-2701.1995.

KAMIMURA, B. A. A Metagenomic Approach to the Study of Microbial Ecology and Safety of Brazilian Artisanal Cheeses: Bacterial diversity of artisanal cheese processing environment from Serra da Canasta region. 2018. $154 \mathrm{f}$. Tese (Doutorado em Ciência de Alimentos) - Universidade Estadual de Campinas, Campinas, 2018.

KAZOU, M. et al. Microbial Flora. In: TOLDRÁ, F.; NOLLET, L. M. L. Handbook of Dairy Foods Analysis. 2. ed: Taylor \& Francis, 2021. cap. 32. p. 673-697. ISBN 9780367343132.

LARSEN, M. V. et al. Multilocus Sequence Typing of Total Genome-Sequenced Bacteria. Journal of Clinical Microbiology, v. 50, n. 4, p.1355-1361, 2012. DOI: $10.1128 / \mathrm{JCM} .06094-11$.

LI, J. et al. Bacterial microbiota of Kazakhstan cheese revealed by single molecule real time (SMRT) sequencing and its comparison with Belgian, Kalmykian and Italian artisanal cheeses. BMC Microbiology, v. 17, n. 1, p. 1-11. DOI: 10.1186 / s12866-016-0911-4.

MAIDEN, M. C. J. et al. Multilocus sequence typing: a portable approach to the identification of clones within populations of pathogenic microorganisms. Proceedings of the National Academy of Sciences of the United States of America, v. 95, n. 6, p. 3140-3145, 1998. DOI: 10.1073/pnas.95.6.3140.

MANGIA, N. P.; FANCELLO, F.; DEIANA, P. Microbiological characterization using combined culture dependent and independent approaches of Casizolu pasta filata cheese. Journal of Applied Microbiology, v. 120, n. 2, p. 329-45, 2016. DOI: 10.1111/jam.13001.

MARDANOV, A. V.; KADNIKOV, V. V.; RAVIN, N. V. Metagenomics: A Paradigm Shift in Microbiology. Metagenomics. 2 ed.: Elsevier, 2018. p. 1-13. DOI: 10.1016/B978-0-08102268-9.00001-X.

MARINO, M. et al. Metagenomic profiles of different types of Italian high-moisture Mozzarella cheese. Food Microbiology, v. 79, p. 123-131, 2019. DOI: 10.1016/j.fm.2018.12.007.

MAUKONEN, J.; SAARELA, M. Microbial communities in industrial environment. Current Opinion in Microbiology, v. 12, n. 3, p. 238-243, 2009. DOI: 10.1016/j.mib.2009.04.002. 
NEBE-VON-CARON, G.; BADLEY, R. A. Viability assessment of bacteria in mixed populations using flow cytometry. Journal of Microscopy, v.179, ed. 1, p.55-66, 1995. DOI: 10.1111/j.1365-2818. 1995.tb03612.x.

NIERMAN, W. C. et al. Genome data: what do we learn? Current Opinion in Structural Biology, v. 10, ed. 3, p. 343-348, 2000. DOI: 10.1016/s0959-440x (00)00094-4.

NOCKER, A.; BURR, M.; CAMPER, A. K. Genotypic Microbial Community Profiling: a Critical Technical Review. Microbial Ecology, v. 54, n. 2, p. 276-289, 2007. DOI: 10.1007/s00248-006-9199-5.

O'SULLIVAN, D. J. et al. Nucleic acid-based approaches to investigate microbial-related cheese quality defects. Frontiers in Microbiology, v. 4, n. 1, p. 1-15, 2013. DOI: 10.3389 / fmicb.2013.00001.

O'SUlLIVAN, O.; COTTER, P. D. Microbiota of Raw Milk and Raw Milk Cheeses. In: MCSWEENEY, P. L. H. et al (ed.). Cheese: Chemistry, Physics and Microbiology: Academic Press, 2017, p. 301-316. DOI: 10.1016/b978-0-12-417012-4.00012-0.

PEHRSON, M. E. de S. F. Efeito da adição de culturas probióticas sobre aspectos microbiológicos e parâmetros fermentativos de Queijo Artesanal das Terras Altas da Mantiqueira. 2017, 128 f. Tese (Doutorado em Biotecnologia Industrial) - Universidade de São Paulo, Lorena, 2017.

PEREIRA, L. S. Qualidade microbiológica e físico-química do queijo coalho comercializado na cidade de São Luís - MA. 2006. Monografia (Graduação em Medicina Veterinária) Setor de Ciências Agrárias, Universidade Estadual do Maranhão, São Luís, 2006.

PÉREZ-LOSADA, M. et al. Pathogen typing in the genomics era: MLST and the future of molecular epidemiology. Infection, Genetics and Evolution, v. 16, p. 38-53, 2013. DOI: 10.1016 / j.meegid.2013.01.009.

RIBEIRO, A. C. et al. Controle microbiológico da vida de prateleira de ricota cremosa. Ciência e Agrotecnologia, v. 29, n. 1, p. 113-117, 2005. DOI: 10.1590/S1413-70542005000100014.

RIOS, D. L. et al. Matatranscriptoma em alimentos: o impacto da expressão gênica do microbioma na saúde humana. In: VERRUCK, Silvani (org.). AVANÇOS EM CIẾNCIA E TECNOLOGIA DE ALIMENTOS. Guarujá: Editora Científica Digital, 2020. Cap. 21. p. 292-306. DOI: 10.37885 / 201001889.

SABAT, A. J. et al. Overview of molecular typing methods for outbreak detection and epidemiological surveillance. Eurosurveillance, v. 18, n. 4, p. 1-15, 2013. DOI: 10.2807/ese.18.04.20380-en.

SALINAS, R.D. Alimentos e nutrição: Introdução à Bromatologia/Rolando D. Salinas; tradução Fátima Murad. - 3 edição - Porto Alegre: Artmed, 2002, p. 278.

SANGER, F.; COULSON, A. R. A rapid method for determining sequences in DNA by primed synthesis with DNA polymerase. Journal of molecular biology, v. 94, n. 3, p. 441-446, 1975. 
DOI: 10.1016 / 0022-2836 (75) 90213-2.

SHARMA, A.; LEE, S.; PARK, Y.-S. Molecular typing tools for identifying and characterizing lactic acid bacteria: a review. Food Science and Biotechnology, v. 29, n. 10, p. 1301-1318, 2020. DOI: 10.1007/s10068-020-00802-x.

SILVA, J. G. Características físicas, físico-químicas e sensoriais do queijo Minas artesanal da Canastra. 2007. 210 p. Dissertação (Mestrado em Ciência dos Alimentos) - Universidade Federal de Lavras, Lavras, 2007.

VAN BELKUN, A. et al. Guidelines for the validation and application of typing methods for use in bacterial epidemiology. Clinical Microbiology and Infection, n. 13, ed. 3, p.1-46, 2007. DOI: $10.1111 / \mathrm{j} .1469-0691.2007 .01786 . \mathrm{x}$.

WOLSKA, K.; SZWEDA, P. Genotyping Techniques for determining the diversity of microorganisms. Genetic Diversity in Microorganisms, p.53-94, 2012. DOI: 10.5772/35101.

ZHANG, J. et al. Evaluation of different $16 \mathrm{~S}$ rRNA gene V regions for exploring bacterial diversity in a eutrophic freshwater lake. Science of the Total Environment, v.618, p. 12541267, 2018. DOI: 10.1016/j.scitotenv.2017.09.228. 